\title{
Assessment of pattern preferences by flower-naïve bumblebees*
}

\author{
François R. SÉGUIN ${ }^{1}$, Catherine M.S. PlOWRIGHT ${ }^{2}$ \\ ${ }^{1}$ Département de biologie, Université d'Ottawa, Ottawa, Ont., Canada K1N 6N5 \\ ${ }^{2}$ École de psychologie, Université d'Ottawa, Ottawa, Ont., Canada K1N 6N5
}

Received 3 April 2007 - Revised 2 October 2007 - Accepted 8 October 2007

\begin{abstract}
Two methods for the assessment of preferences by flower-naïve bumble bees (Bombus impatiens) were compared. Bees with and without prior experience on rewarding patterns were given twenty choices of unrewarding patterns (radial vs. concentric) in a radial arm maze. Either way, a preference for radial patterns was obtained. Prior training on grids of circles, squares or diamonds amplified the preference, whereas training on a ring of circles did not. Prior rewarded experience does not merely draw the bees' attention to the patterns in the maze, or serve as a motivator, but also likely leads to a similarity judgment between training and testing. Given that it was possible to test for the choices of truly flower-naïve bumblebees, training is at best unnecessary and is at worst a source of bias.
\end{abstract}

pattern recognition / bumblebee / Bombus / innate / learning

\section{INTRODUCTION}

When a worker bumblebee leaves its colony the first few times, it not only must learn the location of its nest entrance, but it soon faces the problem of distinguishing potential sources of food from everything else in view. Before discrimination learning through differential reinforcement can occur, bumblebees must first be drawn to objects from which to learn. Odour undoubtedly functions to attract bees to flowers, but researchers have recently endeavoured to determine whether particular visual stimuli also have drawing power: are particular visual aspects of flowers attractive to bees prior to any experience with flowers? A variety of terms have been used to describe behaviour prior to any such experience, and they include "innate" (Lunau, 1990; Lehrer et al., 1995; Heuschen et al., 2005), "spontaneous"

Corresponding author: C.M.S. Plowright, cplowrit@uottawa.ca

* Manuscript editor: Jacqueline Pierre
(Lehrer et al., 1995) and "prepared" (Menzel, 1985). Other variations on the same theme can be found in the animal behaviour literature (species-specific, instinctive, inborn, unlearned, hardwired, pre-programmed, prefunctional, genetically determined, etc.) and several authors have cautioned against confusing them (Bateson, 1984; Oyama, 1985; Hogan, 1988). In this paper, we adopt the terminology of Giurfa et al. (1995): rather than allude to the characteristics and the origins of the behaviour towards flowers encountered for the first time, we refer to the animals themselves as being "flower-naïve", though as described below, this begs the question of what kinds of experience might define the boundary between flower-naïveté and loss of it.

The question of what draws bumblebees to flowers for the first time can be traced back at least to Manning (1956) but empirical research in this area is comparatively new. Only recently have there been reports of the characteristics of floral colour (Lunau 
1990, 1991, 1992; Lunau and Maier 1995; Giurfa et al., 1995; Lunau et al., 1996; Heuschen et al., 2005) and shape (Lehrer et al., 1995; Rodriguez et al., 2004; Simonds and Plowright, 2004; Plowright et al., 2006) that are important either to bumblebees or honeybees. Part of the reason that few studies have investigated the behaviour of flowernaïve bees is methodological: it is much easier to work with trained bees because their movements are quick, directional and purposive. Bees on their first flight out of the colony are exploring their environment and not seeking out previously identified sources of food. Their flights paths meander and indeed, flower-naïve bees often return to the colony with no food at all. In our lab, we have several times observed bumblebees in a flight cage flying, apparently aimlessly, right above blueberry or thistle flowers on which they only landed hours or days later. Even bumblebees in greenhouses, in a confined space containing little else but rows of flowers, take 2-4 days before foraging on tomato flowers (Asada and Ono, 1996).

One commonly used method in this area is to examine the elicited behaviours (approach, antennal contact, landing and even probing) of flower-naïve bees to floral stimuli (e.g., Lunau, 1990, 1991). While this method is naturalistic in that bees are studied in free flight, there are at least two difficulties. The first is that non-approaches are rarely if ever reported and so it is unclear to what extent subject self-selection occurs, and whether to interpret non-approach as a failure to respond to the stimulus or as a failure to be attracted by the stimulus. The second is that the behaviour of "approach" may be difficult both to operationalize and to code. Notwithstanding the distinction between "near orientation" and "far orientation" (Lunau, 1990), the distance at which a bee has been deemed to have "approached" a stimulus varies across several studies ["approach toward a flower dummy from some distance, which usually changes between 1.5 and 0.5 m" (Lunau, 1990, p. 828); "bees visibly slowed down their flight to approach an area to a distance of lower than $5 \mathrm{~mm}$ " (Chittka and Walker, 2006, p. 325); "approach was defined as flying $2 \mathrm{~cm}$ or less above the nectar hole" (Church and Plowright,
2006, p. 135); "approach flights where a bee flew directly towards a cluster to within 10 cm" (Dyer et al., 2007, p. 9)].

An alternative method is to study choice behaviour between two or more stimulus types, which is perhaps a more easily coded response. Using this method, Lehrer et al. (1995) found that honeybees had a preference for radial patterns as well as for symmetrical patterns (their study is described in detail more recently by Giurfa and Lehrer (2001)) and Rodríguez et al. (2004) reported that bumblebees had an "innate" preference for bilateral symmetry. In both these studies, however, bees were given prior rewarded experience on visual stimuli other than the ones presented at the time of testing. In the case of Rodríguez et al., the purpose of using reward on an ostensibly "neutral" (p. 375) stimulus (a plain disk) was not stated, but it may have been to attract bees to a particular area. In the case of Lehrer et al. (1995), the purpose was to lead honeybees to learn a pattern (a grid of squares or a grid of diamonds) that would ostensibly not resemble the testing pattern and would prevent the bees from using any previous experience with natural flowers - in other words, it was to restore naïveté to non-naïve bees.

Using reward prior to testing may well be innocuous, especially if it serves merely to motivate the bees to search for food or to attract the bees' attention to a particular place. Nonetheless, the fact that bees were trained on a rewarding visual stimulus raises the possibility that at the time of testing, the bees were not really flower-naïve, at least if a flower is defined as a visual stimulus associated with reward (Neal et al., 1998). Prior training may not have been "neutral", as supposed by the experimenters, and may well have influenced subsequent choice, perhaps through stimulus generalization. Indeed, experiments on stimulus generalization have shown that the colour choices of bumblebees are controlled by generalization of previously learned colour from training (Gumbert, 2000). Moreover, bees are capable of learning certain parameters from the training pattern and use them to discriminate between novel patterns (van Hateren et al., 1990; Zhang et al., 1992; Srinivasan, 1994). 
The objective of this study is to rule on the neutrality of prior experience. To do so, we manipulated prior experience and then compared the choices of bumblebees between two stimuli: radial vs. concentric. We used a control condition, where bumblebees were tested for their first few choices between stimuli in a radial arm maze on their first time out of the colony. This condition uses truly flowernaïve bees. In the experimental conditions, bees were pre-trained on a variety of stimuli. Grids of squares and grids of diamonds were used since they were used by Lehrer et al. (1995). We hypothesized that the straight lines in these grids might bias choice towards the radial stimulus, contra Lehrer et al.'s untested assumption that the testing stimuli did "not resemble checkerboards" (p. 126). If grids of circles were used instead of grids of squares or diamonds, then the choice of radial vs. concentric stimuli might subsequently be more biased towards the concentric (more circular) stimuli. Though the circles were a salient component of the patterns to us, the grid of circles was nonetheless a linear arrangement of circles. The linear columns and rows may well have been salient to the bees and as such, even a grid of circles might be perceived by the bees as more similar to the radial pattern (with its straight lines) than to the concentric pattern. Accordingly, a second manipulation was subsequently undertaken: a comparison between no-training and a training on a fourth type of training stimulus: a circular arrangement of circles.

The study was designed to answer the following three questions: (1) Do truly flowernaïve bumblebees have a preference for radial patterns? In other words, is preference for the radial pattern above chance when there is no prior training at all; (2) Does prior training to an ostensibly neutral pattern increase their preference for the radial pattern? (3) If so, does the type of training pattern matter?

\section{METHODS}

\subsection{Bees and colonies}

Four colonies of commercially reared bumblebees (Bombus impatiens) were purchased from
Biobest Biological Systems. A reservoir in the nest box underneath the colony gave unlimited access to sugar solution. The reservoir was capped one or two evenings before observations were taken. In this way, the bees were prevented from building up large stores of sugar solution that would dampen any incentive to search for food. Pollen was supplied ad libitum. Each worker was identified with a numbered label glued to its thorax.

\subsection{Apparatus}

A 12-arm radial arm maze was used (diagrammed in Fig. 1). It was modelled on that of Lehrer et al. (1995) and described in Simonds and Plowright (2004) and Plowright et al. (2006). Each corridor $(14 \times 15 \times 15 \mathrm{~cm}, \mathrm{~W} \times \mathrm{L} \times \mathrm{H})$ opened onto a central area ( $22 \mathrm{~cm}$ wide). The corridors' entrances from the central area were $6 \mathrm{~cm}$ wide. The vertical walls of the maze were made from opaque grey Plexiglas. A glass feeding tube $(9.6 \mathrm{~cm}$ long) could be inserted through a hole $(1 \mathrm{~cm}$ in diameter) in the centre of the back wall of each corridor and the floor. The maze's base, which was made of clear Plexiglas $0.32 \mathrm{~cm}$ thick, was placed on a grey sheet. The roof was a removable disc cover $(57.5 \mathrm{~cm}$ wide $)$ made from clear Plexiglas. A white cardboard cylinder (49.5 cm high) surrounded the maze to attenuate any outside distractions. The apparatus was illuminated by daylight from a window and eight fluorescent bulbs on the ceiling. The bulbs were General Electric 32 Watt Starcoat $3500 \mathrm{~K}$ bulbs, model \# F32T8 SPX35, mounted on a ballast of $60 \mathrm{~Hz}$ frequency. Even if the bees could perceive flicker from the bulbs, this factor would be constant over the course of the study. Floral colour discriminations by bumble bees can be impaired if the spectral quality of illumination is changed (Dyer and Chittka, 2004). Our patterns, however, were not coloured but were black and white, and the lighting conditions, albeit with low UV compared to natural light, remained constant.

The colony's nest box was connected to the maze by a wooden walkway ( $30.5 \mathrm{~cm}$ long) so that the bees could enter directly from their colony through one of the corridors. Three glass plates covered the top of the walkway and two pieces of cardboard acting as sliding gates could be slipped through the spaces between the plates to control the comings and goings of the bumblebees into the maze. 


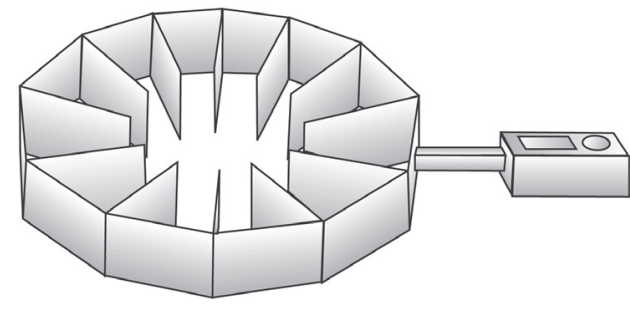

Figure 1. Top view of the experimental apparatus. The colony (on the right) is attached to the radial arm maze (on the left) by a wooden walkway. The maze has 12 corridors with one corridor serving as the entrance.

\subsection{Stimuli}

All the patterns had a small hole $(1 \mathrm{~cm}$ in diameter) pierced through the centre that allowed it to be mounted vertically on a glass feeding tube (empty or full) on the back wall of each of the 12 corridors.

Training patterns. For the experimental groups (Fig. 2), prior to testing on the test patterns described below, the bees were rewarded on a training pattern in the procedure described below. Four patterns were used: three patterns of figures (squares, diamonds or circles) arranged in a grid and one pattern of circles arranged in a ring. The patterns were drawn on a piece of paper $(12.5 \times 14 \mathrm{~cm})$. The grid of squares had 4 rows and 4 columns of squares (each square measuring $3.5 \mathrm{~cm} \times 3.5 \mathrm{~cm}$ ). At the entrance of the corridor, the pattern would subtend a visual angle of $52^{\circ}$. The grid of diamonds had squares of the same dimensions as in the grid of squares, but they were rotated by $90^{\circ}$. The grid of circles consisted of black circles of the same diameter as the width of the squares. As with the squares and diamonds, they were arranged in rows and columns. Finally, the ring of circles consisted of a circular arrangement of eight circles of the same dimensions as in the grid pattern.

Test patterns. The black and white test patterns (see Fig. 2) were a radial pattern with eight alternating wedges and a concentric pattern with four alternating circular bands ( $1.5 \mathrm{~cm}$ wide). These two patterns were chosen from the experiment by Lehrer et al. (1995) because the radial pattern elicited an "innate" marked preference while the concentric pattern was avoided. A model of each test pattern (12 $\mathrm{cm}$ in diameter) was made from white paper and black construction paper. The models were then photocopied to make 6 paper copies of each testing pattern.

\subsection{Procedure}

Phase 1: Training vs. no training. The control groups received no training in the maze and proceeded directly to the testing phase described below. The four experimental groups were trained with one of the four patterns. During training, the pattern was placed in one of the 12 corridors of the radial arm maze. A glass tube containing sugar solution (2:1 water/sugar by volume) protruded from its centre. The 11 other corridors had an empty tube and no pattern. For the sake of efficiency, bees were trained in small groups of workers: usually one to three workers, five at most, depending on how many came out to forage on that day. After two days of food restriction, a group of foragers was trained to enter the maze and obtain a reward from the checkerboard pattern. Once the bumblebee(s) had made four rewarded visits to that corridor, the pattern was moved to another corridor to prevent the bees from learning that one particular corridor was rewarding. Therefore, the training pattern was presented in all the corridors except for corridor \# 1, which serves as the entrance to the maze. The training session ended when each bumblebee had made at least 44 rewarded visits ( 4 times $\times 11$ corridors) to the training pattern. A visit consisted of the bee drinking sugar solution from the tube and flying back to the colony. The training session lasted approximately $2-3$ hours.

Phase 2: Testing. The testing session was done on the same day, immediately following the training session for the experimental groups. For the bees in the control groups, which were given no prior training, testing in the maze was their first experience outside the colony. Six radial patterns and six concentric patterns were placed alternately at the end of each of the 12 corridors of the radial arm maze. No reinforcers were given - the feeding tubes were empty. One bumblebee at a time was allowed to enter the maze from the walkway into the entrance corridor (corridor \# 1). Consequently, the pattern of corridor \# 1 had to be put in position after the bumblebee had entered the maze. The first 20 choices were recorded by one observer, where a choice was defined as flying across an imaginary line halfway through the corridor $(7.5 \mathrm{~cm}$ from the pattern). After testing, the bee was removed from the colony and not tested again. After testing five bumblebees from a colony, the arrangement of the patterns within the maze was changed. The radial and concentric patterns were still alternated but whereas for the first five bumblebees, the radial pattern was in corridor \# 1 , for the remaining five, the pattern in corridor 


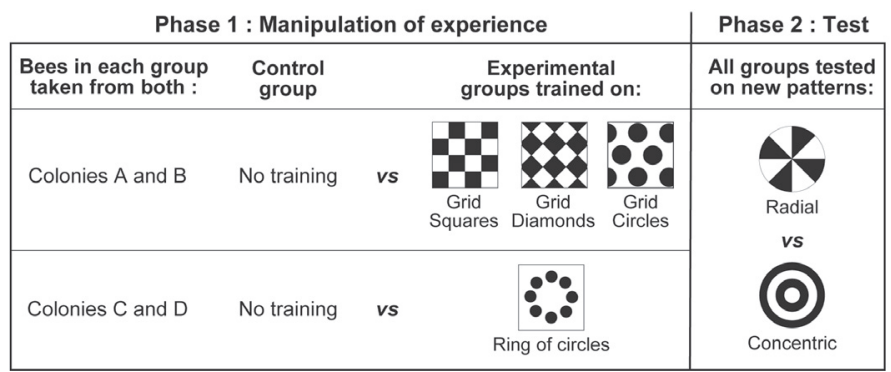

Figure 2. In Phase 1 of the experiment, prior experience was manipulated, with control groups receiving no training and experimental groups being rewarded on the grid of squares, the grid of diamonds, the grid of circles or the ring of circles. In Phase 2, all groups were then tested for their preference of the radial vs. the concentric patterns, both of which were unrewarding.

\# 1 was the concentric pattern-hence any possible bias for the first choice in favour of the pattern in the corridor facing the entrance corridor would be counterbalanced across subjects, with half the subjects facing the concentric pattern and half facing the radial.

\subsection{Design}

First, Colonies A and B were used for the comparison between the control condition and the three experimental conditions with the grid patterns. Then Colonies $\mathrm{C}$ and $\mathrm{D}$ were tested in a control condition (in the same way as Colonies A and B) and in another experimental condition, that with the ring of circles. For each of the 6 conditions (i.e., 2 control conditions and 4 experimental conditions) ten bumblebees from each of two colonies (either colonies $\mathrm{A}$ and $\mathrm{B}$ or colonies $\mathrm{C}$ and $\mathrm{D}$ ) were tested and so the group proportions for each condition are based on 400 choices ( 10 bees $\times 2$ colonies $\times 20$ choices per bee).

\subsection{Statistical analysis}

The data were binary (i.e., choice of radial vs. concentric pattern) and there was replication within bees since each bee made 20 choices. Therefore, a replicated test of Goodness of fit using the Gstatistic (Sokal and Rohlf, 1995) was used for each condition. Two $G$ values were obtained: $G_{H}$ and $G_{P}$. The $G_{H}$ value tests for heterogeneity (i.e., individual differences). The $\mathrm{G}_{p}$ value tests for whether the pooled data (i.e., the group choice proportions) deviated from a theoretical value of chance (50:50).
The $\mathrm{G}$ values are compared to a $\chi^{2}$ value in tests of significance.

In addition to comparing each choice proportion to a theoretical value, we also compared the control and experimental conditions. Using GLIM (Generalized Linear Interactive Modeling) statistical software (Francis et al., 1993), a logistic model, which specifies a binomial error term, was fit to the data. The three experimental conditions involving training with the grid arrangements were compared to the control for Colonies A and B. The experimental condition with the ring of circles was compared to the control for Colonies $\mathrm{C}$ and $\mathrm{D}$.

\section{RESULTS}

Figure 3 shows the group choice proportions for the radial vs. concentric patterns for all conditions.

\subsection{Comparison of choice behavior with chance}

The results of the replicated Goodness of fit test are given in Table I. In all conditions, Control and Experimental, there was a significant $G_{P}$ value, which indicates a significant deviation of the group choice proportions from the chance value of 50:50: on the whole, the radial pattern was chosen over the concentric one.

In the experimental condition with the grid of diamonds, there were significant individual differences (i.e., a significant $\mathrm{G}_{\mathrm{H}}$ ). Partitioning the $G$ value into individual contributions revealed that 11 bees ( 5 from Colony A and 6 
(a)

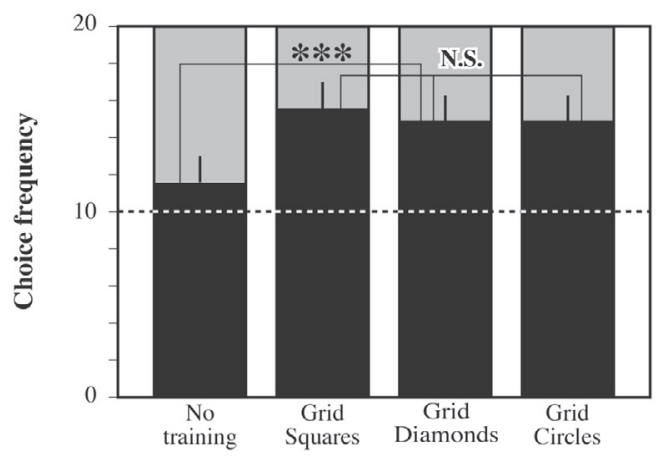

(b)

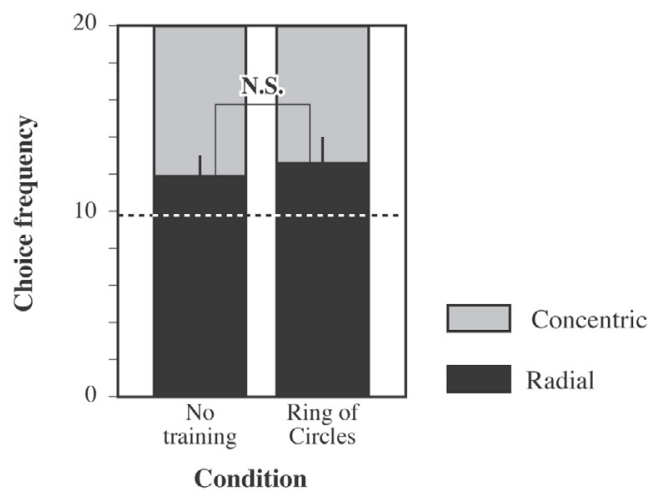

Figure 3. Group choice frequencies, with standard error bars, for the radial and concentric patterns as a function of whether the bees were trained or not. The broken line shows chance performance. (a) A control group vs. groups trained with grids of squares, diamonds or circles. (b) A control group vs. groups trained with a ring of circles. The bracketed conditions were compared. $* * * P<0.00001$. N.S.: non-significant.

from Colony B) had a significant preference for the radial pattern (from 15 to 18 choices out of 20), 9 bees had a non-significant preference for the radial pattern and one had a non-significant preference for the concentric. In short, individual variation is mostly attributable to differences in degree rather than direction of preference. In all the other conditions besides the grid of diamonds, no individual differences were detected.

\subsection{Comparisons among conditions}

Though all groups showed a significant preference for the radial pattern, the preferences shown in the control conditions were weak. For Colonies A and B, a comparison of the control with the three conditions in which bees were trained with grids shows that the choice proportion for the radial pattern at the time of testing increased by $14-18 \%$ after training. The logistic model revealed a significant effect of condition $\left(\chi^{2}=35.68, \mathrm{df}=3\right.$, $P<0.00001)$. When the analysis was repeated without the control condition, however, the effect disappeared $\left(\chi^{2}=2.64, \mathrm{df}=2\right)$, which shows that there are no significant differences among the three experimental conditions.

In contrast with training on the grids of figures, training with the ring of circles had no effect on the preference for the radial pattern. For Colonies C and D, the difference between the control and experimental conditions was not significant $\left(\chi^{2}=0.64, \mathrm{df}=1\right)$.

\section{DISCUSSION}

In answer to our three questions: (1) Without any prior training bumblebees had a significant preference for the black and white radial pattern over the concentric pattern. It is in line with our previous data, using coloured stimuli, in which radial patterns were preferred over plain disks (Plowright et al., 2006) and, in a three-choice test, over plain disks and concentric patterns (Simonds and Plowright, 2004). For both control groups (one using colonies $\mathrm{A}$ and $\mathrm{B}$, the other using colonies $\mathrm{C}$ and $\mathrm{D})$, individual differences were nonsignificant. This again is in line with our previous work (Simonds and Plowright, 2004; Plowright et al., 2006) in which no differences in pattern preferences among colonies were found. The preference obtained in the present study, however, was weak. (2) Training on rewarding grids of diamonds and grids of squares amplified the preference. Even training on a grid of circles, far from shifting choice over to the concentric pattern of circles, did the opposite. At this point, the comparison is limited to experienced vs. inexperienced bees, and 
Table I. Results of replicated Goodness of fit test for each condition. The $G_{P}$ value tests for the deviation of the observed group choice proportions (shown in Fig. 3) from a chance value of 0.5. The $\mathrm{G}_{\mathrm{H}}$ value tests for individual differences. The $\mathrm{G}$ test statistics are tested against a $\chi^{2}$ value.

\begin{tabular}{lcccc}
\hline & $\mathrm{G}_{\mathrm{P}}(\mathrm{df}=1)$ & $P$ & $\mathrm{G}_{\mathrm{H}}(\mathrm{df}=19)$ & $P$ \\
\hline $\begin{array}{l}\text { Colonies A and B } \\
\quad \text { Control: No training }\end{array}$ & 9.04 & 0.002 & 22.54 & $\mathrm{~ns}$ \\
$\quad \begin{array}{l}\text { Experimental: Training with } \\
\quad \text { Grid of Squares }\end{array}$ & 113.66 & $<0.00001$ & 21.77 & $\mathrm{~ns}$ \\
$\quad$ Grid of Diamonds & 78.28 & $<0.00001$ & 35.27 & 0.013 \\
$\quad$ Grid of Circles & 76.43 & $<0.00001$ & 25.71 & $\mathrm{~ns}$ \\
\hline$\quad$ Colonies C and D & & & & \\
$\quad$ Control: No training & 15.31 & 0.0001 & 15.15 & $\mathrm{~ns}$ \\
$\quad \begin{array}{llll}\text { Experimental: Training with } \\
\quad \text { Ring of circles }\end{array}$ & 25.27 & $<0.00001$ & 26.98 & $\mathrm{~ns}$ \\
\hline
\end{tabular}

so the possibility that the difference between control and experimental groups was due to amount (i.e. 44 training trials) of exposure to the maze, rather than type of pattern during training, must be ruled out: (3) The effect of training was specific to the three grid patterns. No effect of training on a ring of circles was obtained, though the amount of exposure to the maze was the same as for the other experimental conditions. Moreover, such an effect would have been expected if training did little else but motivate bees to forage or, by virtue of differential reward in the corridors, draw attention to the end of the corridors. Our data, however, show that if the effect of training is at all to motivate or to focus attention, it is by no means the only effect. The fact that type of training pattern affected subsequent choice of radial vs. concentric patterns is in line with a learning mechanism in which a similarity judgement is made between the training pattern and the testing pattern. Such learning is precisely what the study of flower-naïve bee behavior is meant to preclude.

Our results should be interpreted with four cautions: (1) we suggest that it might be the linearity in the three grids that amplified the preference for the radial patterns (that contained wedge-shaped segments with straight borders): when the linear arrangements were lacking, in the condition where bees were trained with a ring of circles, no such amplification was obtained. Nonetheless, our experiment was not designed to uncover the basis of any similarity judgement. Our purposes were confined to the three questions outlined in the introduction. It remains possible that the three grid patterns and the patterns at the time of testing shared some other crucial characteristics that was lacking with the ring pattern. One such possibility is that they all activated filters for radial patterns (Horridge and Zhang, 1995): perhaps the grid patterns were perceived as elements (squares, diamonds or circles) that were surrounded by other elements radiating from them. (2) The preference for radial over concentric patterns that we have obtained is a relative preference: concentric patterns may well trigger strong responses when they are presented by themselves or in the context of other patterns. (3) Arguably, only the first choice in the maze is made by a completely flower-naïve bee. Subsequent choices may well be affected by the first, even if it is unrewarded. Indeed, we have demonstrated that habituation of pattern choices occurs, as do dishabituation and spontaneous recovery, all in the absence of reward (Plowright et al., 2006). In the present study, however, we obtained preferences for the radial pattern in spite of any possible habituation within 20 choices. (4) Despite the similarities between our procedure and that of Lehrer et al. (1995), there are important differences, beyond the fact that different species were used. In our study, each experimental group of bees was pre-trained on a single pattern while those in the study by Lehrer et al. (1995) were pre-trained on six patterns (three grids of squares and three grids of diamonds of different spatial frequencies) 
presented in a semi-random succession. In the latter case, bees would not be rewarded for approaching a particular spatial frequency, or a particular orientation of contours, or a radial pattern. Nonetheless, all the training stimuli contained angles and straight lines. In the absence of any assessment by Lehrer et al. (1995) of training stimuli that did not contain straight lines (or angles or any other characteristic of the "neutral" patterns that might possibly be used by bees in a future similarity judgement), it is impossible to know whether this was an important dimension that affected subsequent choice.

Although our results were confined to radial vs. concentric patterns and the training patterns we used, there is a general lesson to be learned regarding the practice of training bees and then drawing conclusions regarding "innate preferences" of "flower-naïve" bees. We cannot say what would have happened if, in our experiment, a group of bees had been trained on just the back of the corridor walls (so grey squares) though such a procedure would have introduced a new variable to consider, that of rewarding and non-rewarding the same visual stimulus. We can not say either whether training on rewarding plain homogeneous disks, which are symmetrical along every possible axis, affected subsequent choice for bilateral symmetry in a recent study on ostensibly flower-naïve bumblebees (Rodríguez et al., 2004). We suggest, however, that the question is an empirical one and that similarity to the test stimuli or lack of it cannot be prejudged by the experimenters but must be put to the bees, as we have done. Perhaps the question is not worth pursuing, given that training was unnecessary and it was possible to test bumblebees for their pattern preferences without it.

Though we have argued for testing the pattern preferences of untrained bees, there is one possible objection to testing bees on their first trips from the colony: at first the bees may be not so much embarking on their foraging careers as learning the characteristics of the nest entrance. Indeed, honeybees are known to make at least their first trip outside the nest, and as many as eighteen, without returning food to the hive (Capaldi et al., 2000). These flights, called "orientation flights" or "learning flights" can have ranges that extend several square meters. Orientation flights are also known to occur in bumblebees (Riabinina et al., 2006). In our study in a maze that was $15 \mathrm{~cm}$ high and about half a meter wide, such orientation flights were not feasible. Nonetheless, future studies on the preferences of flower-naïve bumblebees in more naturalistic environments could allow for the possibility of orientation flights prior to testing (if these flights indeed reflect the bee's failure to search for food, rather than the bee's failure to find it). The use of larger scale environments might also permit a determination of what other floral characteristics besides pattern (e.g. odour, colour contrast) might first draw bumblebees to candidate food sources as well as the distance from which they operate.

In this study and others, the question of what attracts bees to flowers in the first place can be framed in classical ethological terms: is there an "innate releasing mechanism" (Lunau, 1990) that responds to floral sign stimuli? As noted by Shettleworth (1998), one drawback of this approach is that key features must be identified on the basis of field observations and tested one at a time. More modern approaches have analyzed how animals classify multidimensional signals both in the field and in the laboratory (for a general review see Shettleworth, 1998; for a review on categorization of visual stimuli in the honeybee, see Benard et al., 2006). For instance, birds and primates can reveal their own classification of vocal stimuli using operant techniques in which they make same/different judgements. Although use of such techniques with bees might have been unthinkable a few years ago, two recent developments suggest that this is no longer the case. The first is the adaptation of operant techniques to bumblebees (Boisvert and Sherry, 2006). The second is the report that invertebrates can form the abstract concepts of Sameness/Difference (Giurfa et al., 2001). Perhaps in the not too distant future, flower-naïve bees may reveal the basis of their own classification of visual stimuli into functional categories such as "definitely a flower", "possibly a flower" and "definitely not a flower". Given the privileged 
relationship that co-evolution has produced between flowers and bees, we will be in no position to argue with their definitions.

\section{ACKNOWLEDGEMENTS}

This work was supported by a research grant to C.M.S.P. from the Natural Sciences and Engineering Research Council of Canada. We thank Pierre Bertrand for his assistance with the graphics and Martine Perreault for constructive comments on the manuscript.

Évaluation de la reconnaissance des formes par des bourdons sans expérience préliminaire sur fleurs.

Bombus / reconnaissance de formes / apprentissage / inné

Zusammenfassung - Festsetzung von Musterpräferenzen bei Hummeln ohne vorherige Sammelerfahrung. Mit diesen Untersuchungen bei Hummeln (Bombus impatiens) sollten drei Fragen beantwortet werden: (1) Zeigen Hummeln, die mit Sicherheit unerfahren im Sammeln auf Blüten sind, eine Präferenz für radiale Muster im Vergleich zu konzentrischen Mustern? (2) Erhöht ein vorheriges Training auf ein angeblich neutrales Muster die Präferenz für ein radiales Muster? (3) Und wenn ja, hat die Struktur des Trainingsmusters einen Effekt? Die Bienen wurden in einem radialen Labyrinth getestet, in dem ihnen 20 nicht belohnte Wahlmöglichkeiten zwischen radialen und konzentrischen Schwarz-Weiß-Mustern angeboten wurden. Die vorherigen Erfahrungen wurden durch folgendes Design festgelegt: keine vorherige Erfahrung mit belohnten Mustern im Labyrinth (Bienen, die zum ersten Mal das Nest verließen) im Vergleich zu vorherigen Erfahrungen mit belohnten Mustern im Labyrinth mit einem von vier Mustertypen (ein Ring von 8 Kreisen bzw. ein Raster von Kreisen, Quadraten oder Rauten, Abb. 2). Unter allen Bedingungen wurden die radialen Muster signifikant häufiger gewählt. Diese Präferenz war aber nur schwach ausgeprägt, wenn die Bienen keine vorherige Erfahrung hatten. Sie wurde dagegen deutlich vergrößert, wenn die Bienen zuvor Erfahrungen mit einem der drei Raster hatten: das Training mit diesen Mustern führt zu einer Überschätzung der nachfolgenden Präferenz für radiale Muster und umgekehrt zu einer Unterschätzung der Präferenz für konzentrische Muster. Die Wahl wurde nicht durch eine vorherige Erfahrung mit dem Ring von Kreisen beeinflusst, das heißt dass die vorherige belohnte Erfahrung weder die Aufmerksamkeit der Bienen verstärkt auf die Muster im Labyrinth lenkte noch deren Motivation erhöhte. Unsere Ergebnisse weisen auf einen Lernmechanismus bei Hummeln hin, bei dem die Ähnlichkeit zwischen Trainings- und Teststimuli abgeschätzt wird. Nehmen wir an, dass wir die spontane Wahl von tatsächlich unerfahrenen Hummeln beobachtet haben, dann ist Training im besten Fall unnötig. Im schlimmsten Fall kann es die Attraktivität der Blütencharakteristik verändern.

\section{Mustererkennung / Hummeln / Bombus / ange- boren / Lernen}

\section{REFERENCES}

Asada S., Ono M. (1996) Crop pollination by Japanese bumblebees, Bombus spp. (Hymenoptera: Apidae): Tomato foraging behavior and pollination efficiency, Appl. Entomol. Zool. 31, 581-586.

Bateson P.P.G. (1984) Genes, evolution and learning, in: Marler B.P., Terrace H.S. (Eds.), The biology of learning, Springer-Verlag, New York, pp. 7588.

Benard J., Stach S., Giurfa M. (2006) Categorization of visual stimuli in the honeybee Apis mellifera, Anim. Cogn. 9, 257-270.

Boisvert M.J., Sherry D.F. (2006) Interval timing by an invertebrate, the bumble bee Bombus impatiens, Current Biol. 16, 1636-1640.

Capaldi E.A., Smith A.D., Osborne J.L., Fahrbach S.E., Farris S.M., Reynolds D.R., Edwards A.S., Martin A., Robinson G.E., Poppy G.M., Riley J.R. (2000) Ontogeny of orientation flight in the honeybee revealed by harmonic radar, Nature 403, $537-$ 540.

Chittka L., Walker J. (2006) Do bees like Van Gogh's Sunflowers? Opt. Laser Technol. 38, 323-328.

Church D.L., Plowright C.M.S. (2006) Spatial encoding by bumblebees (Bombus impatiens) of a reward within an artificial array, Anim. Cogn. 9, 131-140.

Dyer A.G., Chittka L. (2004) Biological significance of distinguishing between similar colours in spectrally variable illumination: bumblebees (Bombus terrestris) as a case study, J. Comp. Physiol. A 190, 105-114.

Dyer A.G., Whitney H.M., Arnold S.E.J., Glover B.J., Chittka L. (2007) Mutations perturbing petal cell shape and anthocyanin synthesis influence bumblebee perception of Antirrhinum majus flower colour, Arthropod-Plant Interactions 1, 45-55.

Francis B., Green M., Payne C. (1993) GLIM: The Statistical System for Generalized Linear Interactive Modelling, Version 4.0, Oxford University Press, New York. 
Giurfa M., Lehrer M. (2001) Honeybee vision and floral displays: from detection to close-up recognition, in: Chittka L., Thomson J.D. (Eds.), Cognitive ecology of pollination, Cambridge University Press, New York, pp. 61-82.

Giurfa M., Núñez J., Chittka L., Menzel R. (1995) Colour preferences of flower-naive honeybees, J. Comp. Physiol. A 177, 247-259.

Giurfa M., Zhang S., Jenett A., Menzel R., Srinivasan M.V. (2001) The concept of sameness and difference in an insect, Nature 410, 930-933.

Gumbert A. (2000) Color choices by bumble bees (Bombus terrestris): innate preferences and generalization after learning, Behav. Ecol. Sociobiol. 48, 36-43.

Heuschen B., Gumbert A., Lunau K. (2005) A generalised mimicry system involving angiosperm flower colour, pollen and bumblebees' innate colour preferences, Plant Syst. Evol. 252, 121137.

Hogan J.A. (1988) Cause and function in the development of behaviour systems, in: Blass E.M. (Ed.), Handbook of behavioral neurobiology, Vol. 9, Plenum Publishing, New York, pp. 63-106.

Horridge G.A., Zhang S.W. (1995) Pattern vision in honeybees (Apis mellifera): Flower-like patterns with no predominant orientation, J. Insect Physiol. 41, 681-688.

Lehrer M., Horridge G.A., Zhang S.W., Gadagkar R. (1995) Shape vision in bees: innate preference for flower-like patterns, Phil. Trans. R. Soc. Lond. B 347, 123-137.

Lunau K. (1990) Colour saturation triggers innate reactions to flower signals: Flower dummy experiments with bumblebees, J. Comp. Physiol. A 166, 827-834.

Lunau K. (1991) Innate flower recognition in bumblebees (Bombus terrestris, B. lucorum; Apidae): Optical signals from stamens as landing reaction releasers, Ethology 88, 203-214.

Lunau K. (1992) Innate recognition of flowers by bumble bees: orientation of antennae to visual stamen signals, Can. J. Zool. 70, 2139-2144.

Lunau K., Maier E.J. (1995) Innate colour preferences of flower visitors, J. Comp. Physiol. A 177, 1-19.
Lunau K., Wacht S., Chittka L. (1996) Colour choices of naive bumble bees and their implications for colour perception, J. Comp. Physiol. A 178, 477489.

Manning A. (1956) Some aspects of the foraging behaviour of bumble-bees, Behaviour 9, 164-201.

Menzel R. (1985) Learning in honey bees in an ecological and behavioral context, in: Hölldobler B., Lindauer M. (Eds.), Experimental Behavioral Ecology, Fischer, Stuttgart, pp. 55-74.

Neal P.R., Dafni A., Giurfa M. (1998) Floral symmetry and its role in plant-pollinator systems: Terminology, distribution and hypotheses, Annu. Rev. Ecol. Syst. 29, 345-373.

Oyama S. (1985) The ontogeny of information: Developmental systems and evolution, Cambridge University Press, New York.

Plowright C.M.S., Simonds V.M., Butler M.A. (2006) How bumblebees first find flowers: Habituation of visual pattern preferences, spontaneous recovery and dishabituation, Learn. Motiv. 37, 66-78.

Riabinina O., Hempel de Ibarra N., Philippides A., Husbands P., Collett T.S. (2006) Active vision in landmark learning by bumblebees, Perception 35 ECVP Abstract Supplement.

Rodríguez I., Gumbert A., Hempel de Ibarra N., Kunze J., Giurfa M. (2004) Symmetry is in the eye of the 'beeholder': Innate preference for bilateral symmetry in flower-naïve bumblebees, Naturwissenschaften 91, 374-377.

Shettleworth S.J. (1998) Cognition, evolution and behaviour, Oxford University Press, New York.

Simonds V.M., Plowright C.M.S. (2004) How do bumblebees first find flowers? Unlearned approach responses and habituation, Anim. Behav. 67, 379386.

Sokal R.R., Rohlf F.J. (1995) Biometry, 3rd ed., W.H. Freeman, New York.

Srinivasan M.V. (1994) Pattern recognition in the honeybee: recent progress, J. Insect Physiol. 40, 183 194.

van Hateren J.H., Srinivasan M.V., Wait P.B. (1990) Pattern recognition in bees: orientation discrimination, J. Comp. Physiol. A 167, 649-654.

Zhang S., Srinivasan M.V., Horridge G.A. (1992) Pattern recognition in honeybees: local and global analysis, Proc. R. Soc. Lond. B 248, 55-61. 